\title{
Human Herpesvirus 6 and 7 Reactivation and Disease Activity in Multiple Sclerosis
}

\author{
Zaiga Nora-Krukle ${ }^{1}$, Svetlana Chapenko ${ }^{1}$, Inara Logina ${ }^{2}$, Andrejs Millers ${ }^{2}$, \\ Ardis Platkajis ${ }^{3}$, Modra Murovska ${ }^{1}$ \\ ${ }^{1}$ August Kirchenstein Institute of Microbiology and Virology, Riga Stradins University, ${ }^{2}$ Department of Neurology \\ and Neurosurgery, Riga Stradins University, ${ }^{3}$ Department of Radiology, Riga Stradins University, Latvia
}

Key words: multiple sclerosis; human herpesvirus 6; human herpesvirus 7; plasma viremia; interleukin 12; tumor necrosis factor $\alpha$.

Summary. Recent studies have focused on the associations between human herpesvirus 6 (HHV-6) and human herpesvirus 7 (HHV-7), and multiple sclerosis (MS).

The aim of this study was to investigate the associations between HHV-6 and HHV-7 reactivation and MS disease activity, and interleukin 12 (IL-12) and tumor necrosis factor $\alpha(T N F-\alpha)$ production.

Material and Methods. The frequency of plasma viremia by nested polymerase chain reaction and transcription of viral mRNA in peripheral blood mononuclear cells by reverse transcriptasepolymerase chain reaction (RT-PCR) of 14 relapsing/remitting $(R R)$ and 14 secondary progressive (SP) MS patients were studied in comparison with clinical manifestation of the disease. Serum concentrations of cytokines $I L-12$ and TNF- $\alpha$ were analyzed by enzyme-linked immunosorbent assay.

Results. Plasma samples from 25 of the 28 MS patients with estimated latent/persistent HHV-6 and/or HHV-7 infection were examined during relapse and remission/relative remission. HHV-6 reactivation was found in 4 of the 7 RRMS and 4 of the 7 SPMS patients, and HHV-7 reactivation was identified in 3 of the 7 RRMS and 1 of the 7 SPMS patients (all in relapse). In 2 of the 3 RRMS patients without viremia in relapse, HHV-6 mRNA transcription was detected. In RRMS and SPMS patients with active HHV-6 and HHV-7 infection in relapse, the serum concentrations of IL-12 and TNF- $\alpha$ were significantly higher than in those with latent virus infection.

Conclusions. HHV-6 and HHV-7 reactivation could be implicated in the exacerbation of MS via activation of Th1 lymphocyte subsets.

\section{Introduction}

Multiple sclerosis (MS) is a demyelinating disease of the central nervous system, the etiology of which is thought to have a possible viral component. Several immunological and molecular studies have supported a relationship between human herpesvirus 6 (HHV-6) and MS (1-11). Moreover, the associations between HHV-6 reactivation and MS disease activity have been observed, suggesting that HHV6 reactivation is implicated in the exacerbation of MS (11-13). The balance between proinflammatory and anti-inflammatory cytokines has been shown to be associated with the disease activity in MS (14). Interleukin 12 (IL-12) is an immunoregulatory cytokine with a broad range of activities including the regulation of cytokine synthesis and selective promotion of T-lymphocyte subpopulation of T-helper type 1 (Th1) development. Th1-type cells producing disease-promoting proinflammatory cytokines,

Correspondence to Z. Nora-Krukle, August Kirchenstein Institute of Microbiology and Virology, Riga Stradins University, Ratsupites 5, 1067 Riga, Latvia. E-mail: zaiga.nora@gmail.com one of which is tumor necrosis factor $\alpha$ (TNF- $\alpha$ ), were found to be a key factor in the onset of autoimmune processes in MS $(15,16)$.

Our previously studies have shown the association of HHV-6 with MS and correlation between HHV-6 reactivation and MS disease activity (17, 18). Although active HHV-7 infection was found more frequently in MS patients than control blood donors, its possible involvement in demyelinating processes has to be elucidated $(17,19)$. HHV-7 is an enveloped, double-stranded DNA beta-herpesvirus that is closely related to HHV-6. Like other herpesviruses, HHV-7 becomes latent after primary infection and can be reactivated (20). This study examined the relationship between the reactivation of both closely related human herpesviruses HHV-6 and HHV-7 and disease activity in relapsing/remitting (RR) and secondary progressive (SP) MS. Plasma viremia and transcription of viral mRNA in PBMCs were used as the markers of HHV- 6 and HHV-7 active infection, and they correlated with clinical and MRI evidence of MS activity as well as 
with serum IL-12 and TNF- $\alpha$ concentrations. The aim of this study was to evaluate the associations between HHV-6 and HHV-7 reactivation and MS disease activity, and IL-12 and TNF- $\alpha$ production.

\section{Material and Methods}

Patients. Twenty-eight randomly selected patients with MS (21 females and 7 males) were examined for evidence of HHV-6 and HHV-7 infection. The mean age of the patients was 37 years (range, 16-59 years). The cohorts were established with the approval of the local Ethics Committee, and all the participants gave informed consent before the examination. A clinical diagnosis of MS was established according to the criteria of McDonald et al. (21) and confirmed by brain MRI. The mean duration of disease was 7 years (range, 1-22 years). Fourteen patients had relapsing-remitting MS (RRMS) and 14 secondary progressive MS (SPMS). All patients had not received immunosuppressive drugs within 3 months before the study.

Brain Magnetic Resonance Imagining. Magnetic resonance imaging (MRI) was carried out according to the standard protocol using a 1.5-T system. The patients were considered to have active inflammatory lesions (positive gadolinium [Gd]-enhanced lesions) when the areas of hyperintensity, compared to surrounding brain parenchyma, were recorded on a T1-weighted MRI scan after intravenous injection of Gd-DTPA (0.1 mmol/kg body weight).

Detection of HHV-6 and HHV-7 Genomic Sequences by Polymerase Chain Reaction. Total DNA was extracted from peripheral blood mononuclear cells (PBMCs) and cell-free plasma. Nested polymerase chain reaction (nPCR) was used for the detection of HHV-6 and HHV-7 genomic sequences. Detection of HHV-6 was carried out according to Secchiero et al. (22) and HHV-7 according to Berneman et al. (23). In our experiments, the sensitivity of HHV-6-specific primers corresponded to 3 copies of the HHV-6 genome and the sensitivity of HHV-7-specific primers to 5 copies of the HHV-7 genome (17).

Detection of HHV-6 and HHV-7 mRNA Transcription by Reverse Transcriptase-Polymerase Chain Reaction. Total RNA was extracted from $5 \times 10^{6} \mathrm{~PB}-$ MCs by the guanidinium isothiocyanate-phenol method using TRI Reagent ${ }^{\mathrm{TM}}$ LS (Sigma, USA) according to the manufacturer's protocol. Reverse transcription was carried out in a $20-\mu \mathrm{L}$ volume according to the manufacturer's protocol (Thermo Fisher Scientific, Lithuania). The samples were then subjected to amplification with the same primers for HHV-6 or HHV-7 as used in the nPCR.

Enzyme-linked immunosorbent assay. A commercial enzyme-linked immunosorbent assay (ELISA) kit (Bender MedSystem, Austria) was used to measure the concentration of IL-12 (p70) and TNF- $\alpha$ in serum samples according to the manufacturer's protocol. Kallikrein (Sigma, USA) (1000 IE/mL) was added to the serum samples to prevent protein degradation.

Statistical Analysis. The serum concentrations of IL-12 and TNF- $\alpha$ are expressed as mean (SD). The Student $t$ test was used to compare continuous variables with a $P$ value of $<0.05$ considered as significant.

\section{Results}

Of the $28 \mathrm{MS}$ patients, 25 had latent/persistent HHV-6 or/and HHV-7 infection. HHV-6 sequence in PBMC DNA was found in 9 (64.3\%) of the 14 patients with RRMS and $9(64.3 \%)$ of the 14 with SPMS; HHV-7 sequence was identified in $10(71.4 \%)$ of the 14 patients with RRMS and 13 $(92.9 \%)$ of the 14 with SPMS. In $7(58.3 \%)$ of the 12 patients with RRMS and $9(69.2 \%)$ of the 13 with SPMS, double infection was detected.

Relationship Between HHV-6 and HHV-7 Reactivation and Disease Activity in Multiple Sclerosis. Cell-free plasma samples from $25 \mathrm{MS}$ patients with latent/persistent HHV-6 and/or HHV-7 infections were examined during the periods of relapse and remission/relative remission. HHV-6 genomic DNA in plasma was detected in 4 of the 7 RRMS and 4 of the 7 SPMS patients examined during the exacerbation period confirmed by the presence of Gd-enhanced lesions on MRI, but not during the period of remission or relative/remission when HHV-6 infection remained latent and Gd-enhanced lesions were absent (Table 1). The transcription of viral mRNA was detected in 2 of the 3 PBMC RNA samples from RRMS patients in an exacerbation phase confirmed by brain MRI, but without HHV-6 plasma viremia. HHV-7 plasma viremia was found in 3 of the 7 RRMS and in 1 of the 7 SPMS patients all being in the period of clinical exacerbation confirmed by the Gd-enhanced lesions on MRI, but not in any of the patients during the period of clinical remission/relative remission and absence of Gd-enhanced lesions on MRI (Table 1). No transcription of HHV-7 mRNA was found in PBMC RNA from 4 RRMS and 6 SPMS patients despite the active phase of the disease and Gd-enhanced lesions on MRI (Table 1). Thus, the reactivation of HHV-6 $(10 / 14 ; 71.4 \%)$ and HHV-7 (4/14; 28.6\%) was detected in MS patients only during the exacerbation phase in both RRMS and SPMS. Two patients with single HHV-7 latent/persistent infection were examined repeatedly in the periods of exacerbation and remission/relative remission (Table 2). Active HHV7 infection was detected only during the clinical exacerbation and MRI positive for Gd-enhanced lesions in both RRMS and SPMS (Table 2). In two RRMS patients with dual HHV-6 and -7 infection in the active phase of the disease confirmed by brain MRI, the reactivation of HHV-7 but not HHV-6 was detected. 
Table 1. Relationship Between HHV-6 and HHV-7 Reactivation and Disease Activity in Multiple Sclerosis

\begin{tabular}{|c|c|c|c|c|}
\hline \multirow{3}{*}{$\begin{array}{l}\text { Markers of Active Viral Infection } \\
\text { and Disease Activity }\end{array}$} & \multicolumn{4}{|c|}{ Type and Phase of Multiple Sclerosis } \\
\hline & \multicolumn{2}{|c|}{ Relapsing/Remitting } & \multicolumn{2}{|c|}{ Secondary Progressive } \\
\hline & Exacerbation & Remission & Exacerbation & Relative Remission \\
\hline HHV-6 DNA in plasma & $4 / 7$ & $0 / 2$ & $4 / 7$ & $0 / 2$ \\
\hline HHV-6 mRNA in PBMCs & $2 / 3$ & $0 / 2$ & $0 / 3$ & $0 / 2$ \\
\hline MRI & $7 / 7$ & $0 / 2$ & $7 / 7$ & $0 / 2$ \\
\hline HHV-7 DNA in plasma & $3 / 7$ & $0 / 3$ & $1 / 7$ & $0 / 6$ \\
\hline HHV-7 mRNA in PBMCs & $0 / 4$ & $0 / 3$ & $0 / 6$ & $0 / 6$ \\
\hline MRI & $7 / 7$ & $0 / 3$ & $7 / 7$ & $0 / 6$ \\
\hline
\end{tabular}

Values are number of positive cases/number of tested cases.

PBMCs, peripheral blood mononuclear cells; MRI, magnetic resonance imaging; HHV-6, human herpesvirus 6;

HHV-7, human herpesvirus 7.

Table 2. Associations Between Activity of HHV-7 Infection and Activities of RRMS and SPMS During Examination of Two Patients in Dynamics

\begin{tabular}{|c|c|c|c|c|c|}
\hline Patients & $\begin{array}{l}\text { Activity Phase } \\
\text { of the Disease }\end{array}$ & $\begin{array}{l}\text { HHV-7 in Plasma } \\
\text { (nPCR) }\end{array}$ & $\begin{array}{l}\text { MRI } \\
\text { Gd+ }\end{array}$ & $\begin{array}{l}\text { IL- } 12, \mathrm{pg} / \mathrm{mL} \\
\text { (ELISA) }\end{array}$ & $\begin{array}{l}\text { TNF- } \alpha, p g / m L \\
\text { (ELISA) }\end{array}$ \\
\hline RRMS & $\begin{array}{l}\text { Exacerbation } \\
\text { Exacerbation } \\
\text { Remission }\end{array}$ & $\begin{array}{l}+ \\
+ \\
-\end{array}$ & $\begin{array}{l}+ \\
+ \\
-\end{array}$ & $\begin{array}{l}21.6 \\
21.2 \\
<5\end{array}$ & $\begin{array}{l}128.4 \\
65.1 \\
12.7\end{array}$ \\
\hline SPMS & $\begin{array}{l}\text { Exacerbation } \\
\text { Exacerbation } \\
\text { Relative remission } \\
\text { Exacerbation }\end{array}$ & $\begin{array}{l}+ \\
+ \\
- \\
+\end{array}$ & $\begin{array}{l}+ \\
+ \\
- \\
+\end{array}$ & $\begin{array}{c}17.3 \\
21.0 \\
<5 \\
22.0\end{array}$ & $\begin{array}{c}136.0 \\
270.0 \\
24.2 \\
147.0\end{array}$ \\
\hline
\end{tabular}

IL-12, interleukin 12; TNF- $\alpha$, tumor necrosis factor $\alpha$; HHV-6, human herpesvirus 6; HHV-7, human herpesvirus 7; MRI, magnetic resonance imaging; ELISA, enzyme-linked immunosorbent assay; RRMS, relapsing-remitting multiple sclerosis; SPMS, secondary progressive multiple sclerosis.

Table 3. Associations Between Serum IL-12 and TNF- $\alpha$ Levels and Activity of HHV-6 and HHV-7 Infections During Different Types and Phases of Multiple Sclerosis

\begin{tabular}{|c|c|c|c|c|c|c|}
\hline \multirow{2}{*}{\multicolumn{2}{|c|}{ Marker and Infection Type }} & \multirow{3}{*}{ Virus } & \multicolumn{4}{|c|}{ Type and Phase of Multiple Sclerosis } \\
\hline & & & \multicolumn{2}{|c|}{ Relapsing/Remitting } & \multicolumn{2}{|c|}{ Secondary Progressive } \\
\hline & & & Exacerbation & Remission & Exacerbation & Relative Remission \\
\hline \multirow{4}{*}{$\begin{array}{l}\text { IL-12, } \\
\mathrm{pg} / \mathrm{mL}\end{array}$} & Active infection & HHV-6 & $24.70(4.10)$ & - & $22.28(1.89)$ & - \\
\hline & & HHV-7 & $20.62(0.96)$ & - & $20.10(1.43)$ & - \\
\hline & Latent infection & HHV-6 & $9.10(3.11)$ & $<5$ & $9.97(1.16)$ & $7.80(3.91)$ \\
\hline & & HHV-7 & $9.10(3.11)$ & $<5$ & $12.04(1.73)$ & $5.97(2.67)$ \\
\hline \multirow{4}{*}{$\begin{array}{l}\text { TNF- } \alpha \text {, } \\
\text { pg/mL }\end{array}$} & Active infection & HHV-6 & $169.95(44.98)$ & - & $106.75(15.28)$ & - \\
\hline & & HHV-7 & $111.40(30.37)$ & - & $184.33(43.00)$ & - \\
\hline & Latent infection & HHV-6 & $22.30(1.00)$ & $17.22(9.23)$ & $51.93(12.25)$ & $52.30(17.91)$ \\
\hline & & HHV-7 & $22.30(1.00)$ & $18.96(8.90)$ & $43.58(6.91)$ & $57.95(21.50)$ \\
\hline
\end{tabular}

Values are given as mean (SD). IL-12, interleukin 12; TNF- $\alpha$, tumor necrosis factor $\alpha$; HHV-6, human herpesvirus 6; HHV-7, human herpesvirus 7.

Influence of HHV-6 and HHV-7 Activation on Serum Levels of $I L-12$ and $T N F-\alpha$. In RRMS and SPMS, the mean serum levels of IL-12 in the disease exacerbation phase and active HHV-6 infection were significantly higher in comparison with the levels in the exacerbation phase with latent HHV-6 infection $(P<0.05$ and $P<0.01$, respectively) (Table 3 ). Similarly, the mean serum concentration of TNF- $\alpha$ in the period of RRMS relapse and active HHV-6 infection was significantly higher compared with that in the periods of relapse and remission when HHV-6 infection was latent $(P<0.05$ and $P<0.025$, respectively). A significant difference was found also between mean serum TNF- $\alpha$ levels during SPMS relapse and active HHV-6 infection, relapse and latent HHV-6 infection, and relative remission $(P<0.05)$ (Table 3$)$.

The mean serum concentrations of IL-12 and TNF- $\alpha$ were significantly higher among the patients in RRMS relapse and with active HHV-7 infection 
in comparison with the concentrations of these interleukins in RRMS patients in relapse and latent HHV-7 infection $(P<0.05)$ (Table 3$)$. In SPMS patients in the exacerbation phase with active HHV-7 infection, the mean serum concentrations of IL-12 and TNF- $\alpha$ were significantly higher compared with the concentrations of these interleukins in the periods of disease activity and relative remission when HHV-7 infection was latent $(P<0.05)$ (Table 3$)$.

High serum levels of IL-12 (23.6 pg/mL and $18.3 \mathrm{pg} / \mathrm{mL}$, respectively) and TNF- $\alpha(190.1 \mathrm{pg} / \mathrm{mL}$ and $62.0 \mathrm{pg} / \mathrm{mL}$, respectively) were detected in two RRMS patients in relapse with $\mathrm{HHV}-7$ reactivation from the background of latent/persistent double infection. Similar data were obtained in the RRMS and SPMS patients with single HHV-7 infection: significantly higher serum levels of IL-12 and TNF- $\alpha$ in the period of relapse and HHV-7 activation in comparison with these indices in the remission period and latent HHV-7 infection were documented $(P<0.05)$ (Table 2). Thus, an obvious association between HHV-6 and HHV-7 reactivation and serum concentrations of IL-12 and TNF- $\alpha$ was demonstrated.

\section{Discussion}

MS is usually diagnosed in the second or third decade of life, and it is difficult to prove a causative association with HHV-6 and HHV-7 infections, which in the event of acute infection during childhood does not usually produce acute after-effects (2). Recently, much attention has been given to the relationship between HHV-6 and MS, but there are only few studies regarding the significance of HHV7 in the etiopathogenesis of MS. HHV-6 and HHV7 are closely related viruses and have very similar biological behavior. Both viruses infect cells of the immune system and thus may modulate their function (24, 25). Since HHV-6 latently infects CD4+ lymphocytes and low-level expression (chronic infection) occurs, HHV-6 protein is represented in the cell membrane, and due to this, T lymphocytes start to treat these cells as foreign. This HHV-6 protein present in the cell membrane has a 10-amino acid homology with myelin basic protein (MBP), so the organism also starts to recognize MBP as foreign, which is the basis of the autoimmune process (25). In our previously studies, the association of HHV-6 with MS and correlation between HHV-6 reactivation and $\mathrm{MS}$ disease activity were reported $(17,18)$. Many researchers consider MS as a CD4+ Th1-mediated inflammatory demyelinating disease $(26,27)$, in the pathogenesis of which, the variety of cytokines are involved either in the induction phase or the effector phase. IL-12 is a cytokine thought to play a major role in the pathogenesis of MS (28); $\mathrm{TNF}-\alpha$ is a critical cytokine in the effector phase. Our study aimed to establish whether a relationship existed between HHV-6 and HHV-7 reactiva- tion and MS disease activity, and IL-12 and TNF- $\alpha$ production. HHV-6 as well as HHV-7 reactivation is demonstrated in RRMS and SPMS patients only during the relapse phase of the disease confirmed by the presence of Gd-enhanced lesions in the brain. Two patients repeatedly in the periods of disease exacerbation and remission/relative remission were examined, and it has been shown for the first time that active HHV-7 infection was detected only during the clinical exacerbation in RRMS and SPMS.

The fact that HHV-6 and HHV-7 genome sequences are not found in the plasma of some RRMS and SPMS patients during flare-ups could be related to the early stage of virus replication when the virus has not lysed the cells yet. This is confirmed by the detection of HHV-6 mRNA transcription in two RRMS patients during a flare-up in spite of the fact that the presence of the virus genome sequence in DNA plasma samples was not found. Moreover, patients with active HHV-6 or HHV-7 infection in relapse demonstrate significantly higher concentrations of proinflammatory cytokines IL-12 and TNF- $\alpha$ in peripheral blood in comparison with patients with latent virus infection in relapse. The recent studies on the function of some herpesvirus genome products and their interaction with the host immune system have suggested that the reactivation of HHV-6 and HHV-7 may act as initiators in the cascade of reactions in the immune system causing a relapse of MS $(14,29)$. Our studies demonstrated the correlation between HHV-6 and HHV-7 reactivation and disease activity in both RRMS and SPMS. Simultaneous virus reactivation and an increase in the concentrations of cytokines IL-12 and TNF- $\alpha$ indicate that these viruses could be implicated in MS exacerbation via activation and proliferation of Th1 lymphocyte subset. Active HHV-6 as well as HHV-7 infection may play at least a cofactor role in the initiation and progression of the MS disease.

\section{Conclusions}

HHV-6 and HHV-7 reactivation could be implicated in the exacerbation of multiple sclerosis via activation of Th1 lymphocyte subsets.

\section{Acknowledgments}

We thank Y. Asano, Fujita Health University, Japan, for the gift of HHV-6 and HHV-7 supernatants of infected cells and S. Dewhurst, University of Rochester Medical Centre, USA, for the gift of HHV-6 and HHV-7 DNA, used as the positive controls in PCR. This study was supported in part by the grant 04.1157 (M.M.) of the Latvian Science Council.

\section{Statement of Conflict of Interest}

The authors state no conflict of interest. 


\section{References}

1. Sola P, Merelli E, Marasca R, Poggi M, Luppi M, Montorsi $\mathrm{M}$, et al. Human herpesvirus 6 and multiple sclerosis: survey of anti-HHV-6 antibodies by immunofluorescence analysis and of viral sequences by polymerase chain reaction. J Neurol Neurosurg Psychiatry 1993;56:917-9.

2. Voumvourakis KI, Kitsos DK, Tsiodras S, Petrikkos G, Stamboulis E. Human herpesvirus 6 infection as a trigger of multiple sclerosis. Mayo Clin Proc 2010;85(11):1023-30.

3. Soldan SS, Berti R, Salem N, Secchiero P, Flamand L, Calabresi PA, et al. Association of human herpes virus 6 (HHV-6) with multiple sclerosis: increased IgM response to HHV-6 early antigen and detection of serum HHV-6 DNA. Nature Med 1997;3:394-7.

4. Ablashi DV, Lapps W, Kaplan M, Whitman JE, Richert JR, Pearson GR. Human herpesvirus-6 (HHV-6) infection in multiple sclerosis: a preliminary report. Mult Scler 1998;4: 490-6.

5. Ablashi DV, Eastman HB, Owen CB, Roman MM, Friedman J, Zabriskie JB, et al. Frequent HHV-6 reactivation in multiple sclerosis (MS) and chronic fatigue syndrome (CFS) patients. J Clin Virol 2000;16:179-91.

6. Friedman JE, Lyons MJ, Cu G, Ablashi DV, Whitman JE, Edgar M, et al. The association of human herpesvirus- 6 and MS. Mult Scler 1999;5:355-62.

7. Ongradi J, Rajda C, Marodi CL, Csiszar A, Vecsei L. A pilot study on the antibodies to HHV-6 variants and HHV-7 in CSF of MS patients. I NeuroVirol 1999;5:529-32.

8. Berti R, Soldan SS, Akhyani N, McFarland HF, Jacobson S. Extended observations on the association of HHV-6 and multiple sclerosis. J NeuroVirol 2000;6 Suppl 2:S85-7.

9. Alvarez-Lafuente R, Martin-Estefania C, de las Heras V, Castrillo C, Picazo JJ, Valera de Seijas E, et al. Active human herpesvirus 6 infection in patients with multiple sclerosis. Arch Neurol 2002;59:929-33.

10. Cirone M, Cuomo L, Zompetta C, Ruggieri S, Frati L, Faggioni A, et al. Human herpesvirus 6 and multiple sclerosis: a study of T-cell cross-reactivity to viral and myelin basic protein antigens. J Med Virol 2002;68:268-72.

11. Behzad-Behbahani A, Mikaeili MH, Entezam M, Mojiri A, Pour GY, Arasteh MM, et al. Human herpesvirus-6 viral load and antibody titer in serum samples of patients with multiple sclerosis. I Microbiol Immunol Infect 2011; 44(4):247-51.

12. Berti R, Brennan MB, Soldan SS, Ohayon JM, Casareto L, McFarland HF, et al. Increased detection of serum HHV-6 DNA sequences during multiple sclerosis (MS) exacerbations and correlation with parameters of MS disease progression. J NeuroVirol 2002;8:250-6.

13. Alvarez-Lafuente R, De las Heras V, Bartolome M, Picazo IJ, Arroyo R. Relapsing-remitting multiple sclerosis and human herpesvirus 6 active infection. Arch Neurol 2004;61:1523-7.

14. van Boxel-Dezaire AH, Hoff SC, van Oosten BW, Verweij CL, Drager AM, Ader HJ, et al. Decreased interleukin-10 and increased interleukin-12 p40 mRNA are associated with disease activity and characterize different disease stages in multiple sclerosis. Ann Neurol 1999;45:695-703.

15. Trinchieri G. Interleukin-12: a cytokine produced by anti- gen-presenting cells with immunoregulatory functions in the generation of T-helper cells type 1 and cytotoxic lymphocytes. Blood 1994;84:4008-27.

16. Zhang S, Kaplan MH. The p38 mitogen-activated protein kinase is required for IL-12 induced IFN-gamma expression. J Immunol 2000;165:1374-80.

17. Tomsone V, Logina I, Millers A, Chapenko S, Kozireva S, Murovska M. Association of human herpesvirus 6 and human herpesvirus 7 with demyelinating diseases of the nervous system. J Neuro Virol 2001;7:564-9.

18. Chapenko S, Millers A, Nora Z, Logina I, Kukaine R, Murovska M. Correlation between HHV-6 reactivation and multiple sclerosis disease activity. J Med Virol 2003;69:111-7.

19. Kozireva S, Nemceva G, Danilane I, Pavlova O, Blomberg J, Murovska M. Prevalence of blood-borne viral infections (cytomegalovirus, human herpesvirus-6, human herpesvirus-7, human herpesvirus-8, human T-cell lymphotropic virus-I/II, human retrovirus-5) among blood donors in Latvia. Ann Hematol 2001;80:669-73.

20. Koch WC. Fifth (human parvovirus) and sixth (herpesvirus 6) diseases. Curr Opin Infect Dis 2001;14:343-56.

21. McDonald WI, Compston A, Edan G, Goodkin D, Hartung HP, Lublin FD, et al. Recommended diagnostic criteria for multiple sclerosis: guidelines from the International Panel on the diagnosis of multiple sclerosis. Ann Neurol 2001;50(1):121-7.

22. Secchiero P, Carrigan DR, Asano Y, Benedetti L, Crowley RW, Komaroff AL, et al. Detection of human herpesvirus 6 in plasma of children with primary infection and immunosuppressed patients by polymerase chain reaction. I Infect Dis $1995 ; 171: 273-80$.

23. Berneman ZN, Ablashi DV, Li G, Eger-Fletcher M, Reitz MS Jr, Hung CL, et al. Human herpesvirus 7 is a T-lymphotropic virus and is related to, but significantly different from, human herpesvirus 6 and human cytomegalovirus. Proc Natl Acad Sci USA 1992;89:10552-6.

24. Atedzoe BN, Menezes J, D’Addario M, Xu J, Ongradi J, Ahmad A. Modulatory effects of human herpes virus-7 on cytokine synthesis and cell proliferation in human peripheral blood mononuclear cell cultures. I Leukoc Biol 1999; 66:822-8

25. Tejada-Simon MV, Zang YC, Hong J, Rivera VM, Zhang JZ. Cross-reactivity with myelin basic protein and human herpesvirus-6 in multiple sclerosis. Ann Neurol 2003;53: 189-97.

26. Hafler DA. Multiple sclerosis. J Clin Invest 2004;113:78894.

27. Grigoriadis N, Hadjigeorgiou GM. Virus-mediated autoimmunity in multiple sclerosis. J Autoimmune Dis 2006;3:1.

28. Makhlouf K, Weiner HL, Khoury SJ. Increased percentage of IL-12+ monocytes in the blood correlates with the presence of active MRI lesions in MS. I Neuroimmunol 2001; 119:145-9.

29. Behzad-Behbahani A, Mikaeili MH, Entezam M, Mojiri A, Pour GY, Arasteh MM, et al. Human herpesvirus-6 viral load and antibody titer in serum samples of patients with multiple sclerosis. J Microbiol Immunol Infect 2011; 44(4):247-51.

Received 13 September 2011, accepted 31 October 2011 